\title{
REDESAIN RUANG TERBUKA HIJAU KAMPUS UNSRAT \\ BERDASARKAN EVALUASI KENYAMANAN TERMAL \\ DENGAN INDEKS DISC
}

\section{REDESIGN UNSRAT CAMPUS GREENSPACE REGARDING TO EVALUATION OF THERMAL COMFORT BY DISC INDEX}

\author{
Fabiola B. Saroinsong1), Josephus I. Kalangi'1), dan Prestin Babo') \\ 1)Program Studi Ilmu Kehutanan, Fakultas Pertanian Unsrat Manado, 95115 \\ 2)Alumni Program Studi IImu Kehutanan, Fakultas Pertanian Unsrat Manado, 95115
}

\begin{abstract}
Outdoor spaces are important to sustainable cities because they accommodate outdoor activities and contribute greatly to the quality of urban living.During the last decade, interest in the assessment of thermal comfort has increased because of climate changes and increased heat stress in cities. Greenspaces that provide a pleasurable thermal comfort experience for users effectively improve their quality of livability and productivity. However, current investigations lack a general framework for the use of thermal comfort assessment, such as in making master plan or designing better greenspace. This paper discusses greenspace of Sam Ratulangi University Campus relating to thermal comfort. It provides knowledge of thermal comfort investigation and landscape design review. The results of thermal comfort assessment, among 11 observed plots, only greenspace at FMIPA is categorized as comfortablespot. Greenspaces at FAPET and FEB are not really comfortable, those at BNI and FKM A and FKM $B$ are not comfortable and those at FATEK, FAPERTA, FISIP, FH, FKM A are categorized as very uncomfortable spots. We suggest some options for redesigningof uncomfortable and very uncomfortable greenspace spots.
\end{abstract}

Keywords: greenspace, outdoor, termal comfort

\begin{abstract}
ABSTRAK
Ruang luar adalah penting untuk kota-kota berkelanjutan karena mengakomodasi aktivitas-aktivitas luar dan sangat besar berkontribusi pada kualitas hidup perkotaan. Selama dekade terakhir, ketertarikan dalam penilaian kenyamanan termal meningkat karena adanya perubahan-perubahan iklim dan peningkatan stress panas di perkotaan. Ruang Terbuka Hijau (RTH) yang menyediakan kenyamanan termal bagi pengguna secara efektif akan meningkatkan daya hidup dan produktivitas mereka. Bagaimanapun, investigasi-investigasi yang dilakukan masih kurang dalam hal penerapan konsep penilaian kenyamanan termal pada pembuatan master plan atau desain RTH yang lebih nyaman. Tujuan penelitian ini adalah mengevaluasi kenyamanan kenyamanan termal RTH Kampus UNSRAT berdasarkan Indeks DISC dan mendiskusikan pilihan redesain untuk meningkatkan kenyamanan termal. Hasil perhitungan kenyamanan termal di Kampus Unsrat menunjukkan bahwa RTH yang masuk kategori nyaman yaitu FMIPA. RTH FAPET, FPIK, dan FEB tergolong kategori agak tidak nyaman. RTH yang tergolong kategori tidak nyaman yaitu yang terletak di Bank BNI dan FKM A. RTH FAPERTA, FATEK, FISIP, FH, FKM A, dan FKM B dikategorikan sangat tidak nyaman berdasarkan kenyamanan termal. Beberapa pertimbangan redesain disarankan untuk meningkatkan kenyamanan termal RTH kampus UNSRAT.
\end{abstract}

Kata kunci: kenyamanan termal, ruang luar, ruang terbuka hijau 


\section{PENDAHULUAN}

Ruang terbuka hijau (RTH) merupakan area memanjang atau jalur dan mengelompok, yang penggunaannya lebih bersifat terbuka, tempat tumbuh tanaman, baik yang tumbuh secara alamiah maupun yang sengaja ditanam (UU No.26 Tahun 2007 tentang penataan ruang). RTH menyediakan banyak layanan ekosistem seperti menyaring udara dan mengurangi polusi udara, meredam kebisingan, meningkatkan infiltrasi air dan mengisi ulang air tanah, menyediakan makanan, menopang kehidupan satwa liar, meningkatkan kesehatan manusia, menciptakan naungan dan meningkatkan kenyamanan termal (Dahmann, Wolch, JoassartMarcelli, Reynolds \& Jerret, 2010; Escobedo, Kroeger \& Wagner, 2011; Roy, Byrne \& Pickering, 2012; Villeneuve, et al., 2012).

Kenyamanan termal dinyatakan sebagai rasa panas atau dingin yang dirasakan oleh tubuh manusia dan wujud respon dari sensor perasa yang terdapat pada kulit terhadap stimuli suhu yang ada di sekitarnya. Sensor perasa berperan menyampaikan informasi rangsangan rasa kepada otak di manan otak akan memberikan perintah kepada bagian-bagian tubuh tertentu agar melakukan antisipasi guna mempertahankan suhu tubuh agar tetap berada pada sekitar $37^{\circ} \mathrm{C}$, hal ini diperlukan agar organ dalam tubuh dapat menjalankan fungsinya secara baik (Karyono, 2016). Sangkertadi (2013) mendefinisikan kenyamanan adalah suatu keadaan dimana manusia merasakan dan menyatakan setuju dengan kondisi lingkungan di suatu tempat. Kenyamanan termal secara umum merupakan perasaan yang nyaman dengan keadaan termal yang ada di lingkungan sekitar tubuh. Situasi kenyamanan termal senantiasa dikaitkan dengan situasi klimatik seperti suhu udara, kelembaban udara, dan kecepatan angin yang merupakan bagian-bagian dari iklim mikro. Iklim mikro merupakan kondisi iklim pada suatu ruang yang sangat terbatas, tetapi komponen iklim ini penting artinya bagi kehidupan manusia, tumbuhan dan hewan, karena kondisi udara pada skala mikro ini yang akan berkontak langsung (dan mempengaruhi secara langsung) dengan makhluk-makhluk hidup tersebut (lek, Moniaga, dan Sangkertadi, 2014).
American Society of Heating, Refrigerating, and AirConditioning Engineers (ASHRAE) menentukan enam parameter dasar yang mempengaruhi sensasi termal secara simultan, yaitu: temperatur udara, kelembaban relatif, kecepatan angin, temperatur radiasi rata-rata, aktivitas, dan pakaian. Suatu area dinyatakan nyaman atau memiliki kenyaman termal yang baik bila di tempat tersebut manusia berhasil meminimalkan pengeluaran energi dari dalam tubuhnya dalam rangka menyesuaikan (mengadaptasi) terhadap lingkungan termal di sekitarnya. Indeks DISC (discomfort scale) adalah salah satu cara menganalisis kenyamanan termal dari pengukuran iklim mikro, yang dirumuskan oleh Gagge and Berglund (1985) dalam Sangkertadi (2013).

Studi tentang kenyamanan termal ruang luar termasuk desain ruang terbuka hijau untuk ameliorasi iklim mikro mendapat perhatian dalam dekade terakhir. Kebanyakan penelitian dilakukan di lingkungan perkotaan dimana peningkatan temperatur karena pertumbuhan struktur buatan cepat dan pengaruhnya terhadap populasi dalam jumlah yang besar (Chen and Ng, 2012; Nortonet, et.al., 2013; Zinn and Fitzsimons, 2014; Brown, et al., 2015). Meski demikian, penelitian kenyamanan termal ruang luar (outdoor) masih lebih sedikit dibanding yang dilakukan di dalam ruangan (indoor). Selain itu, aplikasi investigasi ameliorasi iklim dalam proses desain RTH masih kurang (Chen and $\mathrm{Ng}$, 2012; Wolch, Byrne and Newell, 2014; Walls, Parker and Walliss, 2015).

Penelitian ini bertujuan untuk mengevaluasi kenyamanan termal RTH Kampus UNSRAT berdasarkan Indeks DISC dan mendiskusikan pilihan redesain untuk meningkatkan kenyamanan termal.

\section{METODE PENELITIAN}

Penelitian ini dilaksanakan di RTH Kampus Universitas Sam Ratulangi Manado pada bulan November - Desember 2015.

Alat dan bahan yang digunakan dalam penelitian ini adalah thermo-hygrometer digital, anemometer, solarimeter, GPS, caliper, meteran, klinometer, kamera, alat tulis menulis, kuesioner responden dan seperangkat komputer. 
Pemilihan plot pengamatan didasarkan pada kriteria yaitu RTH Kampus UNSRAT yang sering diakses oleh mahasiswa maupun dosen. Dari hasil survei diperoleh 11 RTH yang sesuai dengan kriteria, yaitu Fakultas Matematika dan IImu Pengetahuan Alam (FMIPA), Fakultas Pertanian (FAPERTA), Fakultas Peternakan (FAPET), Bank BNI Kampus (Bank BNI), Fakultas Perikanan dan IImu Kelautan (FPIK), Fakultas Teknik (FATEK), Fakultas Ekonomi dan Bisnis (FEB), Fakultas IImu Sosial dan Politik (FISPOL), Fakultas Hukum (FH), Fakultas Kesehatan Masyarakat A (FKM A), dan Fakultas Kesehatan Masyarakat B (FKM B) dengan lokasi seperti pada Gambar 1.

Variabel yang diamati yaitu: suhu udara, kelembaban udara, kecepatan angin, intensitas cahaya matahari, ukuran fisiologis responden (berat dan tinggi badan), suhu tubuh dan pakaian responden.

Pengukuran suhu, kelembaban, kecepatan angin dan intensitas cahaya matahari dilakukan dua kali dalam sehari yaitu jam 10.00-11.00 pagi dan 14.00-15.00 siang, dengan pengulangan sebanyak tiga kali untuk setiap RTH. Pengukuran dilakukan pada saat langit cerah dan tidak dalam kondisi hujan. Suhu dan kelembaban udara diukur menggunakan alat thermo-hygrometer digital, untuk mendpatkan nilai suhu dan kelembaban yang akurat, alat didiamkan selama 5 menit kemudian diambil data minimum dan maksimum dari alat kemudian dijumlahkan lalu dibagi dua sehingga mendapatkan data suhu dan kelembaban. Kecepatan angin menggunakan anemometer dengan cara mendiamkan alat di bawah pohon pada masing-masing RTH kemudian nilai kecepatan angin akan muncul pada alat. Intensitas cahaya matahari menggunakan solarimeter, pengukuran dilakukan pada luar dan dalam tajuk saat pengukuran diluar tajuk solarimeter tidak akan berfungsi jika terkena cahaya matahari langsung sehingga digunakan kertas untuk menutupi bagian atas alat agar dapat memperoleh keakuratan. Pengukuran dilakukan baik di luar maupun di dalam tajuk RTH.

Pengambilan data ukuran fisiologis, suhu tubuh dan pakaian responden dilakukan pada pengunjung masing-masing RTH tersebut yang dipilih secara acak. Berat dan tinggi badan didapat dari responden sendiri. Suhu tubuh dan suhu pakaian diukur menggunakan alat pengukur suhu infra red. Pengukuran suhu tubuh responden dilakukan dengan cara mengarahkan infra red dari alat ke bagian leher responden dengan jarak 1-2 meter dari pengukur.

Data tambahan yang diambil yaitu data tanaman yang meliputi nama pohon, diameter, tinggi pohon, tebal kanopi, dan tinggi bebas cabang.

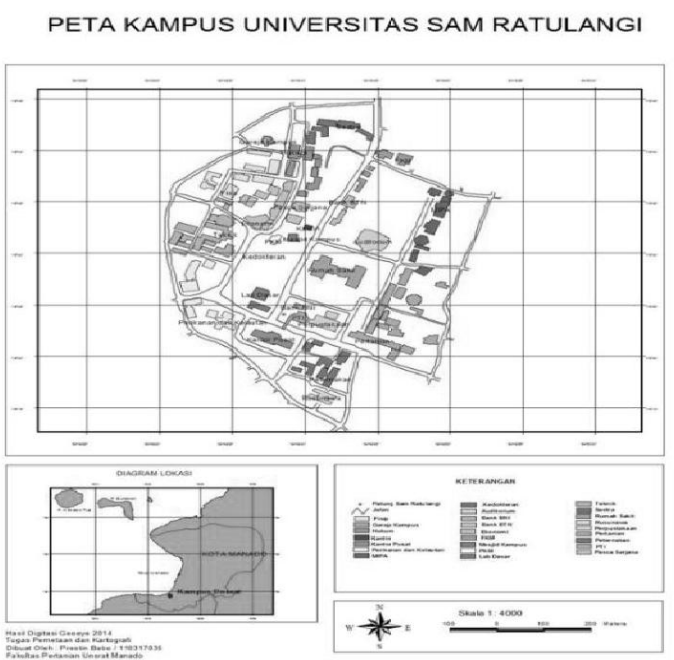

Gambar 1. Peta Kampus UNSRAT dan 11 Plot Pengamatan

(Figure 1. Map of UNSRAT Campus and 11 Observation Plots) 
Data iklim mikro yang diperoleh selanjutnya dikolaborasikan dengan ukuran fisiologis responden dalam sebuah perhitungan indeks DISC. Data hasil pengukuran iklim mikro akan dianalisis kenyamanan termalnya menggunakan index DISC (discomfort scale) yang dirumuskan oleh Gagge and Berglund (1985) sebagai berikut.

$D I S C=3.9338$ Mcut +0.0158 Ds -0.3348 dimana Mcut adalah persentase perbandingan antara luas kulit basah karena keringat terhadap luas kulit total (\%), dan $D s$ adalah debit atau volume keringat $\left(\mathrm{cm}^{3} / \mathrm{h}\right)$.

Hasil perhitungan index DISC dimasukan dalam pola 5 skala untuk mendapatkan hasil kenyamanan termal (Gagge dan Berglund, 1985) seperti terlihat pada Tabel 1.

Setelah hasil kenyamanan termal diperoleh dalam bentuk pola 5 skala kemudian dibuat dalam bentuk persentase yang nantinya akan dibandingkan dengan persepsi responden. Untuk mendapatkan data persentase kenyamanan termal yaitu dengan cara menjumlahkan masing-masing kenyamanan termal yang diperoleh kemudian dibahagi dengan jumlah keseluruhan responden dan dikalikan 100.

\section{HASIL DAN PEMBAHASAN}

\section{Iklim Mikro dan Kondisi RTH Setiap Plot}

Faktor-faktor iklim mikro yang mempengaruhi kenyamanan termal yaitu suhu udara, kelembaban udara, kecepatan angin, dan intensitas cahaya matahari. Data iklim mikro dari hasil penelitian luar dan dalam tajuk disajikan pada Tabel 2.

Tabel 2 menunjukkan kondisi iklim mikro yang diukur di luar tajuk dan dalam tajuk. Nilai intensitas radiasi matahari di dalam tajuk jelas lebih rendah dibanding dengan yang ada di luar tajuk karena adanya naungan kanopi. Kawasan yang ditumbuhi pohon peneduh memberikan efek tajuk pohon yang menahan radiasi matahari secara langsung. Sehingga suhu di bawah teduhan akan lebih rendah dibandingkan suhu di ruang terbuka. Intensitas radiasi matahari tertinggi di luar tajuk pada RTH FMPA menempati urutan teratas (161.9 $\mathrm{W} / \mathrm{m}^{2}$ ), dan yang terendah adalah pada RTH Bank BNI $\left(99.5 \mathrm{~W} / \mathrm{m}^{2}\right)$. Intensitas radiasi matahari tertinggi di dalam tajuk pada RTH FAPET menempati urutan teratas $\left(68.7 \mathrm{~W} / \mathrm{m}^{2}\right)$, dan yang terendah adalah pada RTH Bank BNI $\left(15.0 \mathrm{~W} / \mathrm{m}^{2}\right)$. Suhu dalam tajuk yang terendah yaitu di FMIPA sebesar $30,1^{\circ} \mathrm{C}$ dan yang tertinggi tercatat di sebesar $32,8^{\circ} \mathrm{C}$. Suhu luar tajuk terendah dan tertinggi berturut-turut diamati di FATEK $32,9^{\circ} \mathrm{C}$ dan di BNI $36,0^{\circ} \mathrm{C}$. Kelembaban udara terendah teramati pada luar tajuk RTH FKM B (56.9\%), dan tertinggi yaitu di bagian dalam tajuk RTH FEB (74.0\%). Kecepatan angin di luar tajuk lebih tinggi dibanding dalam tajuk, dan yang menempati posisi teratas adalah di RTH FAPET.

Vegetasi penyusun RTH dan struktur perkerasan berbeda-beda untuk setiap plot (Gambar 212). Terdapat 11 jenis pohon yang tersebar di RTH FMIPA dengan jumlah total 72 pohon. Dominansi tertinggi yaitu Mahoni Swietenia mahagoni dengan jumlah 39 pohon, selanjutnya Swietenia sp dengan jumlah 14 pohon, dan Angsana Pterocarpus indicus dengan jumlah 5 pohon sedangkan 5 jenis pohon yaitu Kayu besi Intsia bijuga, Buton darat Barringtonia racemosa, Sempur Dillenia retusa, Alpukat Persea americana, dan Laping kubu Melanolepis multiglandulosa masing-masing hanya terdapat satu pohon saja. Pohon yang terbesar yaitu mahoni Swietenia mahagoni dengan tinggi pohon mencapai $17,5 \mathrm{~m}$ dan diameter pohon 78,98. RTH FKM A memiliki jumlah pohon terendah dari semua lokasi penelitian yang ada, hanya jenis vegetasi yaitu Angsana Pterocarpus indicus sejumlah 3 pohon. RTH FKM B hanya memiliki 2 jenis pohon yaitu Palem raja Roystonea regia 2 pohon kemudian Angsana Pterocarpus indicus 1 pohon.

\section{Kenyamanan Termal Berdasarkan Hasil Perhitungan Indeks DISC}

Hasil perhitungan kenyamanan termal berdasarkan Indeks DISC setiap RTH yang diamati dapat dilihat pada Tabel 3. Hasil perhitungan indeks DISC untuk FMIPA didapat nilainya berkisar antara $-0,73-0,40$ (pagi) dan $-1,05--0,19$ (siang). FAPERTA berkisar antara 1,72 - 2,95 (pagi) dan $-0,83-1,72$ (siang). FAPET berkisar antara $-1,89-$ 1,37 (pagi) dan siang 1,23-2,20. Bank BNI berkisar antara 1,18-2,08 untuk pagi, dan 1,23-1,53 untuk siang. FPIK berkisar antara 0,62 - 1,86 (pagi), dan 0,62 - 1,86 (siang). FATEK berkisar antara 0,84-3,65 (pagi), dan 0,49-2,48 (siang). FEB berkisar antara 0,04 - 0,81 untuk pagi, dan 0,82 - 2,57 untuk siang. FISIP berkisar antara 
2,06 - 3,56 untuk pagi, dan 0,75 - 3,09 untuk siang. $\mathrm{FH}$ berkisar antara 2,02 - 3,62 (pagi), dan 1,60 - 2,31 (siang). FKM A berkisar antara 1,03 -
2,40 (pagi), dan 1,11 - 2,45 (siang). FKM B berkisar antara 0,76-2,87 (pagi), dan 1,05-2,68 (siang).

Tabel 1. Pola Skala Kenyamanan Termal Gagge dan Berglund (1985)

(Table 1. Gagge and Berglund Termal Comfort Scale (1985)) Model Skala

Definisi

\begin{tabular}{ll}
\hline & $\leq 0=$ nyaman \\
skala numeris non dimensional khusus untuk lingkungan & $>0-1=$ agak tidak nyaman \\
beriklim panas & $>1-2=$ tidak nyaman \\
& $>2-3=$ sangat tidak nyaman \\
& $>3-4=$ tidak dapat ditoleransi \\
\hline
\end{tabular}

Tabel 2. Rata-Rata Intensitas Radiasi Matahari, Suhu, Kelembaban, dan Kecepatan Angin di Luar Tajuk dan Dalam Tajuk

(Table 2. Average of Sun Radiant Intensity, Temperature, Humidity, and Wind Velocity Inner and Outer Canopy)

\begin{tabular}{|c|c|c|c|c|c|c|c|c|}
\hline \multirow[t]{2}{*}{ Titik Pengamatan } & \multicolumn{2}{|c|}{$\begin{array}{l}\text { Intensitas radiasi } \\
\text { matahari }\left(\mathrm{W} / \mathrm{m}^{2}\right)\end{array}$} & \multicolumn{2}{|c|}{$\begin{array}{l}\text { Suhu } \\
\left({ }^{\circ} \mathrm{C}\right)\end{array}$} & \multicolumn{2}{|c|}{ Kelembaban (\%) } & \multicolumn{2}{|c|}{$\begin{array}{c}\text { Kecepatan angin } \\
(\mathrm{m} / \mathrm{s})\end{array}$} \\
\hline & Luar & Dalam & Luar & Dalam & Luar & Dalam & Luar & Dalam \\
\hline FMIPA & 161.9 & 22.6 & 33.9 & 30.1 & 59.7 & 67.7 & 1.5 & 1.0 \\
\hline FAPERTA & 138.9 & 23.0 & 33.4 & 31.7 & 61.5 & 72.1 & 1.9 & 1.3 \\
\hline FAPET & 121.9 & 68.7 & 34.0 & 31.3 & 61.0 & 65.4 & 2.2 & 0.6 \\
\hline BANK BNI & 99.5 & 32.5 & 34.3 & 32.8 & 58.0 & 59.9 & 1.8 & 0.7 \\
\hline FPIK & 134.3 & 45.6 & 33.4 & 31.3 & 61.2 & 65.9 & 1.7 & 0.8 \\
\hline FATEK & 135.3 & 25.6 & 32.9 & 30.8 & 64.3 & 71.1 & 1.3 & 0.3 \\
\hline FEB & 109.1 & 15.0 & 33.4 & 31.7 & 67.7 & 74.0 & 0.6 & 0.4 \\
\hline FISIP & 141.7 & 51.0 & 33.5 & 32.4 & 63.5 & 69.8 & 1.0 & 0.3 \\
\hline $\mathrm{FH}$ & 128.1 & 30.7 & 33.9 & 31.9 & 64.1 & 70.8 & 1.1 & 1.2 \\
\hline FKM A & 119.3 & 43.6 & 34.7 & 32.2 & 65.9 & 70.0 & 0.5 & 0.2 \\
\hline FKM B & 128.1 & 38.1 & 36.0 & 32.4 & 56.9 & 66.3 & 1.5 & 0.4 \\
\hline
\end{tabular}

Tabel 3. Hasil Perhitungan Indeks DISC di RTH yang Diamati

(Table 3. DISC Index Calculation Results for Every Plot)

\begin{tabular}{|r|c|c|c|c|c|c|c|c|c|c|c|c|c|c|c|c|c|c|c|c|c|c|c|}
\hline No & \multicolumn{2}{|c|}{ FMIPA } & FAPERTA & \multicolumn{2}{c|}{ FAPET } & \multicolumn{2}{c|}{ BANK BNI } & \multicolumn{2}{c|}{ FPIK } & \multicolumn{2}{c|}{ FATEK } & \multicolumn{2}{c|}{ FEB } & \multicolumn{2}{|c|}{ FISIP } & \multicolumn{2}{|c|}{ FH } & \multicolumn{2}{c|}{ FKM A } & FKM B \\
\hline & pagi & siang & pagi & siang & pagi & siang & pagi & siang & pagi & siang & pagi & siang & pagi & siang & pagi & siang & pagi & siang & pagi & siang & pagi & siang \\
\hline 1 & -0.56 & -0.30 & 2.20 & -0.83 & 0.76 & 1.89 & 1.22 & 1.46 & 0.88 & 0.83 & 0.84 & 1.17 & 0.77 & 0.82 & 3.58 & 2.06 & 3.16 & 1.61 & 2.13 & 1.11 & 2.54 & 2.68 \\
\hline 2 & -0.61 & -1.05 & 2.69 & 1.34 & -1.89 & 1.91 & 1.34 & 1.23 & 0.99 & 0.86 & 2.12 & 2.16 & 0.66 & 2.57 & 2.84 & 1.56 & 3.08 & 2.24 & 1.30 & 2.38 & 1.70 & 1.84 \\
\hline 3 & -0.07 & -0.19 & 2.44 & 0.24 & -0.93 & 2.08 & 1.18 & 1.31 & 1.06 & 0.62 & 2.72 & 0.92 & 0.31 & 1.31 & 2.86 & 1.43 & 2.02 & 1.88 & 2.07 & 1.34 & 1.08 & 1.05 \\
\hline 4 & -0.73 & -0.26 & 2.74 & 1.72 & 0.41 & 1.23 & 2.08 & 1.26 & 0.87 & 0.74 & 3.05 & 2.00 & 0.81 & 1.87 & 2.88 & 0.75 & 2.55 & 1.60 & 1.85 & 1.92 & 2.87 & 2.33 \\
\hline 5 & 0.40 & -0.32 & 2.84 & 1.65 & 0.26 & 2.20 & 1.46 & 1.53 & 0.96 & 0.84 & 1.76 & 1.49 & 0.04 & 1.10 & 2.84 & 0.81 & 2.15 & 2.15 & 1.97 & 2.45 & 0.76 & 2.64 \\
\hline 6 & & -0.60 & 2.95 & 1.51 & 0.39 & & & 1.43 & 1.10 & 1.10 & 2.95 & 0.49 & 0.43 & 1.57 & 2.64 & 3.09 & 3.62 & 2.31 & 1.03 & 2.19 & 0.91 & 2.62 \\
\hline 7 & & & 1.72 & 0.27 & 1.37 & & & & 1.05 & 1.86 & 3.65 & 2.10 & & 0.91 & 2.06 & 2.37 & 2.78 & & 1.91 & 2.17 & 1.87 & 2.08 \\
\hline 8 & & & 2.89 & & 0.75 & & & & 0.75 & 1.22 & 2.16 & 2.48 & & & 2.99 & 2.50 & & & 2.05 & 1.85 & 2.12 & 2.10 \\
\hline 9 & & & 2.72 & & -0.64 & & & & 1.06 & 0.64 & & 2.05 & & & 2.30 & 2.67 & & & 2.40 & & & 1.69 \\
\hline 10 & & & 2.71 & & 0.05 & & & & 0.62 & 0.89 & & & & & & 2.20 & & & 1.99 & & & 1.72
\end{tabular}




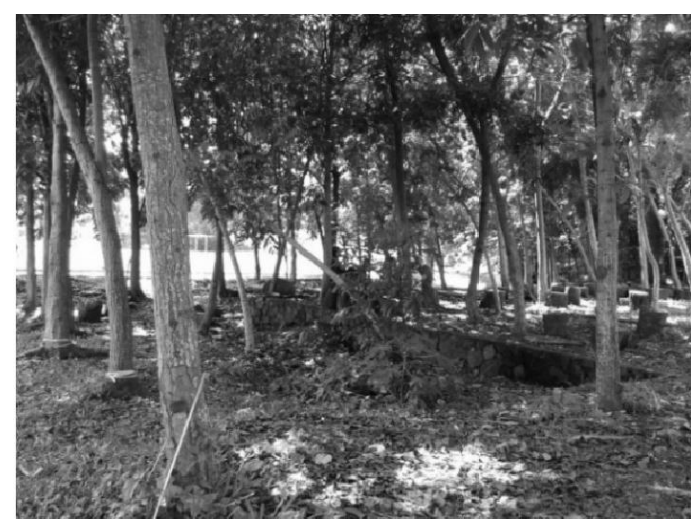

Gambar 2. RTH FMIPA

(Figure 2. Greenspace at FMIPA)

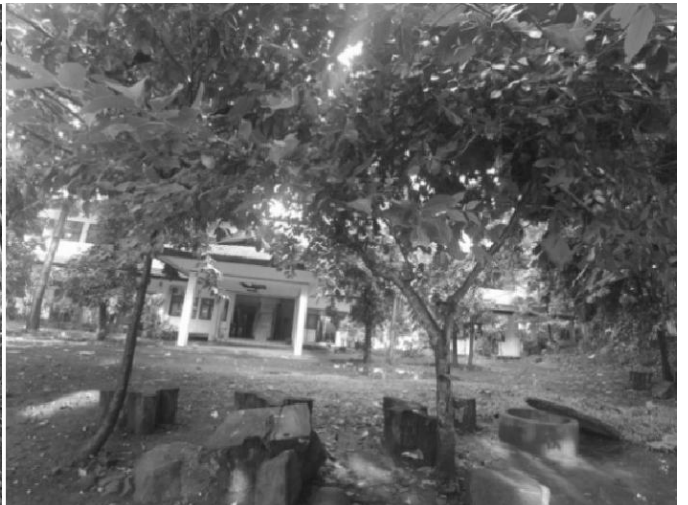

Gambar 3. RTH FAPERTA

(Figure 3. Greenspace at FAPERTA)

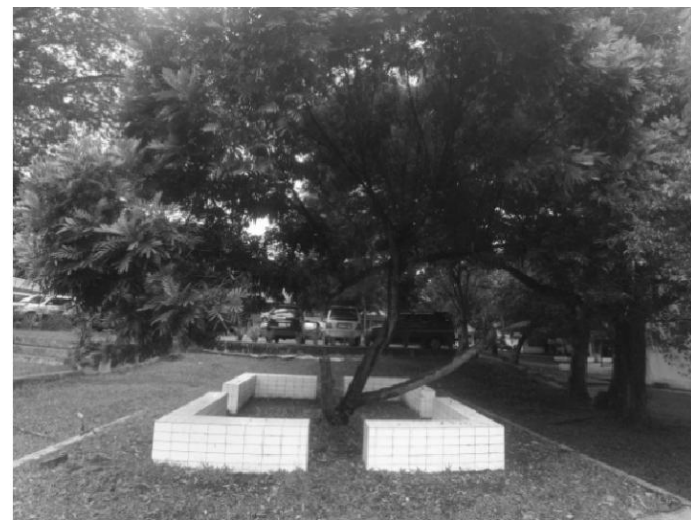

Gambar 4. RTH FAPET

(Figure 4. Greenspace at FAPET)

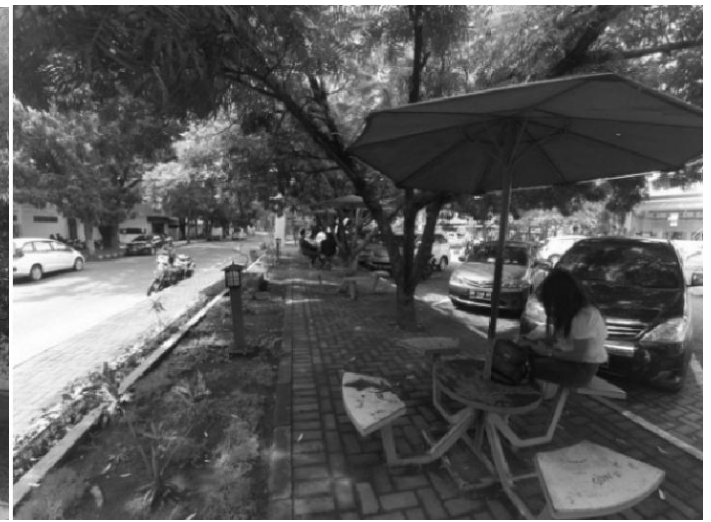

Gambar 5. RTH BNI Kampus UNSRAT

(Figure 5. Greenspace at UNSRAT Campus BNI)

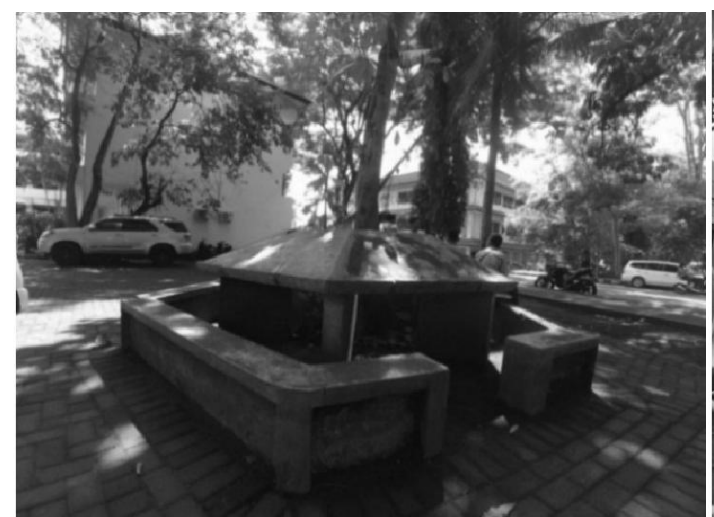

Gambar 6. RTH FPIK

(Figure 6. Greenspace at FPIK)

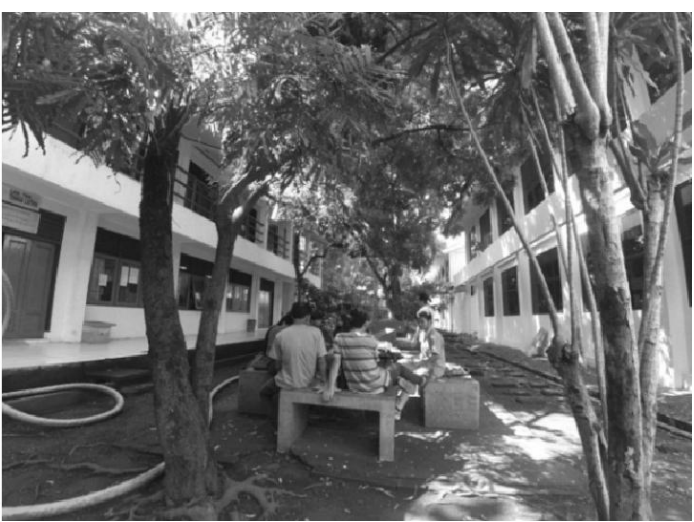

Gambar 7. RTH FATEK

(Figure 7. Greenspace at FATEK) 


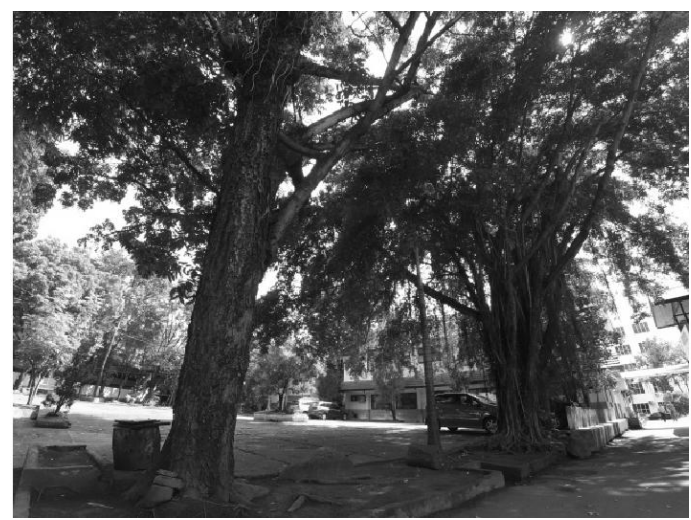

Gambar 8. RTH FEB

(Figure 8. Greenspace at FEB)

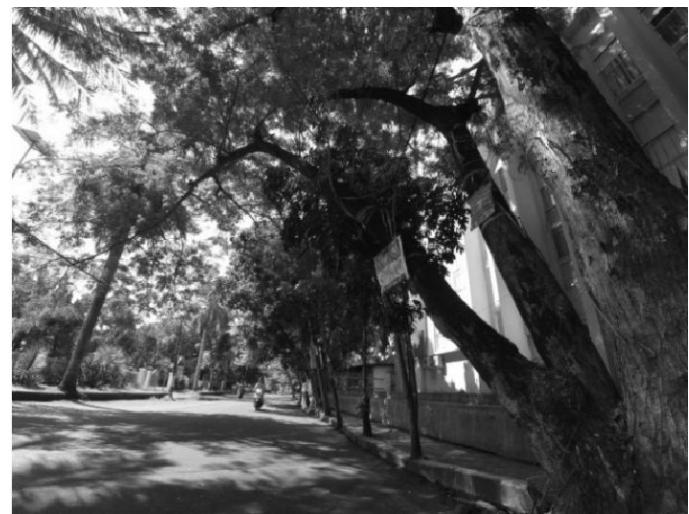

Gambar 10. RTH FH

(Figure 10. Greenspace at FH)

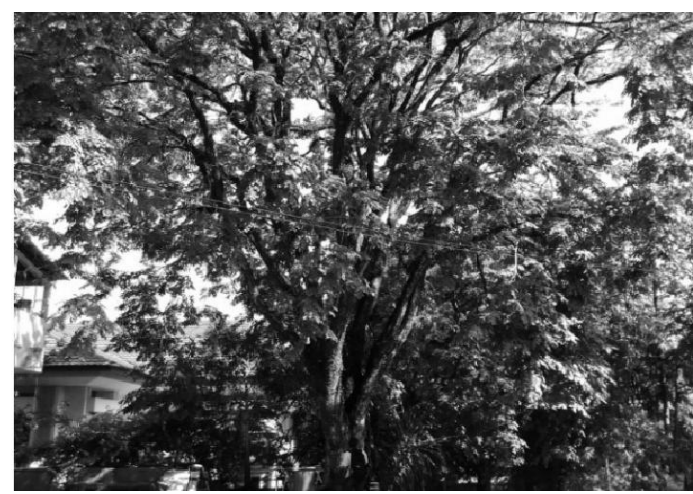

Gambar 12. RTH FKM B

(Figure 12. Greenspace at FKM B)

Nilai indeks DISC ini dinyatakan dalam skala kenyamanan termal Gagge dan Berglund, diperoleh hasil seperti Tabel 4. Hasil pernyataan skala kenyamanan termal untuk FMIPA didapat berkisar antara N - ATN (pagi) dan N (siang). FAPERTA berkisar antara TN - STN (pagi) dan N TN (siang). FAPET berkisar antara N - TN (pagi)

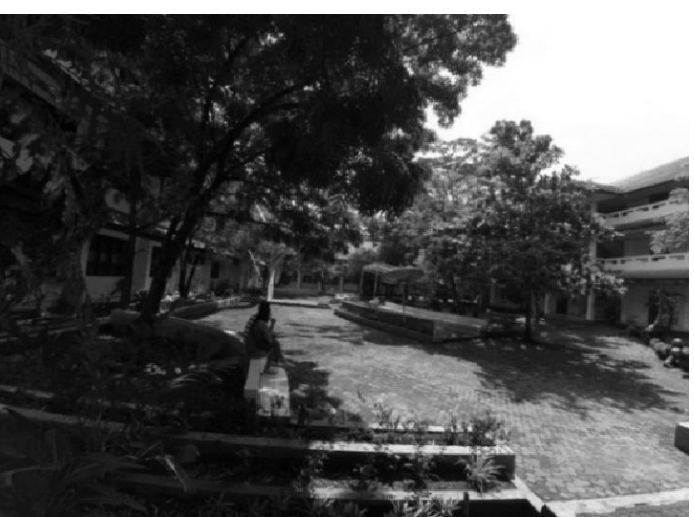

Gambar 9. RTH FISIP

(Figure 9. Greenspace at FISIP)

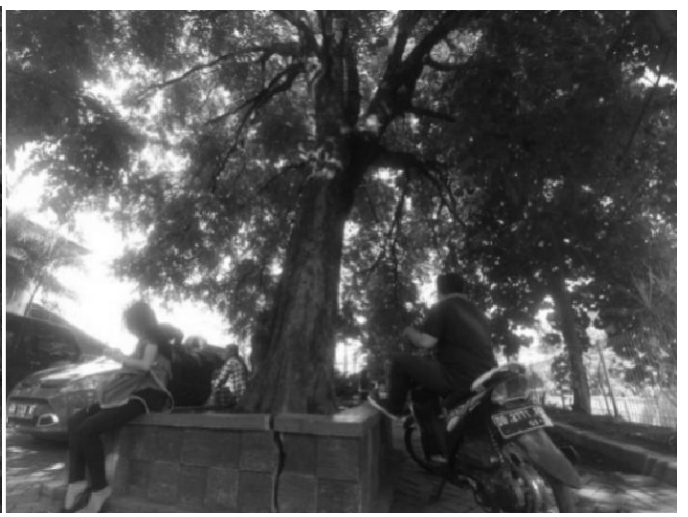

Gambar 11. RTH FKM A

(Figure 11. Greenspace at FKM A) dan siang TN - STN. Bank BNI berkisar antara TN - STN untuk pagi, dan TN untuk siang. FPIK berkisar antara ATN - TN (pagi), dan ATN - TN (siang). FATEK berkisar antara ATN - TDD (pagi), dan ATN - STN (siang). FEB ATN untuk pagi, dan ATN - STN untuk siang. FISIP berkisar antara STN - TDD untuk pagi, dan ATN - TDD untuk 
siang. FH berkisar antara STN - TDD (pagi), dan TN - STN (siang). FKM A berkisar antara TN STN (pagi), dan TN - STN (siang). FKM B berkisar antara ATN - STN (pagi), dan TN - STN (siang).

Persentase skala kenyamanan termal setiap RTH yang diamati di Kampus Unsrat dapat dilihat pada Tabel 5.Kenyamanan dari hasil perhitungan selain menggunakan data iklim mikro, juga menggunakan data fisiologis responden seperti berat dan tinggi badan. Hasil penelitian menunjukan RTH FMIPA merupakan ternyaman dengan nilai 90,9\%, kemudian diikuti dengan FAPET 17,65\% nyaman, dan FAPERTA 5,88\% nyaman. Sedangkan RTH lainnya tidak ada yang nyaman.

Kenyamanan termal merupakan rasa nyaman untuk tinggal atau beraktivitas pada suatu objek/kawasan (Anggiani, 2010). Berdasarkan pengamatan, pada beberapa plot RTH keberadaan pohon peneduh kurang, dan untuk sebagian plot kondisi tersebut ditambah dengan dominansi struktur perkerasan seperti beton, aspal, paving, dan bangunan (Gambar 2-12). Vegetasi memodifikasi iklim dan menghemat penggunaan energi bangunan melalui tiga cara utama, yaitu: a) teduhan mengurangi jumlah panas yang diserap dan disimpan oleh bangunan. b) evapotranspirasi mengubah air menjadi uap air dan mendinginkan udara. c) kanopi pohon memperlambat angin sehingga mengurangi panas yang hilang dari rumah, terutama pada benda dengan konduktivitas yang tinggi (misalnya, kaca jendela) (Uhangkayo, 2012).

RTH FAPERTA mendapat hasil perhitungan STN (Sangat Tidak Nyaman) walaupun memiliki cukup banyak pohon. Terlihat pada Gambar 3, pohon-pohon di sekitar tempat-tempat duduk tidak rapat bahkan menciptakan ruang yang cukup besar untuk terpapar sinar matahari. Sementara RTH FMIPA (Gambar 2) yang memiliki kenyamanan termal sangat nyaman, pohon-pohon lebih rapat dengan kanopi yang bersambung. Selain itu tempat duduk pada RTH FAPERTA bersebelahan langsung dengan parkiran mobil dan terletak di depan jalan. Walaupun panas dari radiasi matahari yang menembus tajuk sama dengan RTH FMIPA, namun dengan adanya pantulan dari benda-benda lain mengakibatkan suhu menjadi lebih hangat.

Suhu udara yang ada di luar tajuk cukup tinggi, dan tajuk pepohonan RTH menurunkan nilai suhu udara sekitar $1,1-3,8^{\circ} \mathrm{C}$. Perbedaan suhu udara dalam dan luar tajuk yang terbesar di RTH FMIPA yaitu $3,8^{\circ} \mathrm{C}$, penurunan yang cukup besar ini tidak lepas dari adanya peran vegetasi. Vegetasi yang dominan di RTH FMIPA yaitu mahoni dengan jumlah 39 pohon. Berdasarkan data tanaman penyerap $\mathrm{CO}_{2}$ oleh Artiningrum (2013) menunjukkan bahwa pohon mahoni termasuk salah satu dari sembilan pohon penyerap $\mathrm{CO}_{2}$ terbesar dengan jumlah penyerapan yaitu $295,73 \mathrm{~kg} /$ pohon/tahun.

Tabel 4. Skala Kenyamanan Termal Titik-titik Pengamatan

(Table 4. Termal Comfort Scale for Every Plot)

\begin{tabular}{|c|c|c|c|c|c|c|c|c|c|c|c|c|c|c|c|c|c|c|c|c|c|c|}
\hline No & \multicolumn{2}{|c|}{ FMIPA } & \multicolumn{2}{|c|}{ FAPERTA } & \multicolumn{2}{|c|}{ FAPET } & \multicolumn{2}{|c|}{ BANK BNI } & \multicolumn{2}{|c|}{ FPIK } & \multicolumn{2}{|c|}{ FATEK } & \multicolumn{2}{|c|}{ FEB } & \multicolumn{2}{|c|}{ FISIP } & \multicolumn{2}{|c|}{ FH } & \multicolumn{2}{|c|}{ FKM A } & \multicolumn{2}{|c|}{ FKM B } \\
\hline & pagi & siang & pagi & siang & pagi & siang & pagi & siang & pagi & siang & pagi & siang & pagi & siang & pagi & siang & pagi & siang & pagi & siang & pagi & siang \\
\hline $1 \mathrm{I}$ & & $\mathrm{N}$ & STN & $\mathrm{N}$ & ATN & TN & TN & $\mathrm{TN}$ & ATI & ATN & ATN & $\mathrm{TN}$ & ATN & ATN & TDD & STN & TDD & $\mathrm{TN}$ & STN & TN & STN & STN \\
\hline 21 & & $\mathrm{~N}$ & STN & TN & $\mathrm{N}$ & TN & TN & $\mathrm{TN}$ & ATI & ATN & STN & STN & ATN & STN & STN & TN & TDD & STN & STN & STN & TN & $\mathrm{TN}$ \\
\hline 31 & & $\mathrm{~N}$ & STN & ATN & $\mathrm{N}$ & STN & $\mathrm{TN}$ & $\mathrm{TN}$ & $\mathrm{TN}$ & ATN & STN & ATN & ATN & $\mathrm{TN}$ & STN & $\mathrm{TN}$ & STN & $\mathrm{TN}$ & STN & $\mathrm{TN}$ & $\mathrm{TN}$ & $\mathrm{TN}$ \\
\hline 4 I & & $\mathrm{N}$ & STN & TN & ATN & TN & STN & TN & ATI & ATN & TDD & TN & ATN & TN & STN & ATN & STN & TN & TN & TN & STN & STN \\
\hline & ATN & $\mathrm{N}$ & STN & TN & ATN & STN & TN & TN & ATI & ATN & $\mathrm{TN}$ & $\mathrm{TN}$ & ATN & $\mathrm{TN}$ & STN & ATN & STN & STN & TN & STN & ATN & STN \\
\hline 6 & & $\mathrm{~N}$ & STN & $\mathrm{TN}$ & ATN & & & $\mathrm{TN}$ & $\mathrm{TN}$ & $\mathrm{TN}$ & STN & ATN & ATN & $\mathrm{TN}$ & STN & TDD & TDD & STN & $\mathrm{TN}$ & STN & ATN & STN \\
\hline 7 & & & TN & ATN & TN & & & & TN & TN & TDD & STN & & ATN & STN & STN & STN & & TN & STN & TN & STN \\
\hline 81 & & & STN & & ATN & & & & ATI & TN & STN & STN & & & STN & STN & & & STN & TN & STN & STN \\
\hline 9 & & & STN & & $\mathrm{N}$ & & & & $\mathrm{TN}$ & ATN & & STN & & & STN & STN & & & STN & & & $\mathrm{TN}$ \\
\hline \begin{tabular}{|r|}
10 \\
\end{tabular} & & & STN & & ATN & & & & ATI & ATN & & & & & & STN & & & TN & & & $\mathrm{TN}$ \\
\hline
\end{tabular}

Keterangan : N : Nyaman, ATN : Agak Tidak Nyaman, TN : Tidak Nyaman, STN : Sangat Tidak Nyaman, TDD : Tidak Dapat Ditoleransi 
Tabel 5. Persentase Kenyamanan Termal

(Table 5. Termal Comfort Percentage)

\begin{tabular}{clcccccc}
\hline \multirow{2}{*}{ No. } & \multirow{2}{*}{ Nama RTH } & Jumlah & \multicolumn{7}{c}{ Persentase (\%) } \\
\cline { 5 - 8 } & Sample & $\mathrm{N}$ & ATN & TN & STN & TDD \\
\hline 1. & FMIPA & 11 & 90.9 & 9.1 & 0 & 0 & 0 \\
2. & FAPERTA & 17 & 5.882 & 11.8 & 29.4 & 52.9 & 0 \\
3. & FAPET & 15 & 17.65 & 35.3 & 23.5 & 11.8 & 0 \\
4. & Bank BNI & 11 & 0 & 0 & 90.9 & 9.1 & 0 \\
5. & FPIK & 20 & 0 & 65 & 35 & 0 & 0 \\
6. & FATEK & 17 & 0 & 17.6 & 23.53 & 47.1 & 0 \\
7. & FEB & 13 & 0 & 61.5 & 30.8 & 7.69 & 0 \\
8. & FISIP & 19 & 0 & 10.5 & 10.5 & 68.4 & 10.5 \\
9. & FH & 13 & 0 & 0 & 23.1 & 53.8 & 23.07 \\
10. & FKM A & 18 & 0 & 0 & 50 & 50 & 0 \\
11. & FKM B & 18 & 0 & 11.1 & 38.89 & 50 & 0 \\
\hline
\end{tabular}

Keterangan : N : Nyaman, ATN : Agak Tidak Nyaman, TN : Tidak Nyaman, STN : Sangat Tidak Nyaman TDD : Tidak Dapat Ditoleransi

Kelembaban yang tinggi pada RTH FEB terjadi karena adanya penguapan dari beberapa faktor seperti vegetasi, manusia, dan kolam. Walaupun vegetasi yang ada di RTH FEB tergolong sedikit, namun dengan adanya kolam yang dekat dengan RTH menyebabkan kelembabannya menjadi tinggi melalui proses penguapan.

Terdapat empat jenis penutup tanah yang tersebar di 11 plot pengamatan yaitu aspal, beton, rumput dan serasah pohon, dan paving. Jenis penutup tanah aspal hanya terdapat pada satu lokasi yaitu FEB, selanjutnya beton terdapat pada $2 \mathrm{RTH}$ yaitu FKM A dan FPIK, rumput dan serasah pohon juga terdapat di 2 RTH yaitu FMIPA dan FAPERTA, dan yang terbanyak yaitu paving yang tersebar di 5 RTH berbeda yaitu Bank BNI, FPIK, FATEK, FISIP, FH, dan FKM B. Penelitian Maidinita, Hardiman, dan Prianto (2009) mengenai suhu udara pada beberapa area dengan perbedaan jenis perutupan lahan menunjukkan terdapat perbedaan antara suhu di RTH yang jenis penutup tanahnya rumput dan serasah pohon dan yang memiliki penutup tanah paving, aspal, maupun material keras lainnya. Pemakaian material rumput pada ruang luar untuk menggantikan sebagian paving sebagai penutup lapisan tanah bisa membantu terciptanya kenyamanan termal.

Kecepatan angin di bawah tajuk lebih lambat jika dibandingkan dengan kecepatan angin di ruang terbuka. Hal ini dikarenakan tajuk pohon yang beragam dapat memperlambat kecepatan angin, dan angin juga akan membawa uap dingin dari bawah teduhan ke lingkungan sekitar. Sehingga suhu udara dan kelembaban udara di bawah teduhan cenderung stabil. Hasil studi menunjukkan bahwa kecepatan angin yang menyentuh tubuh manusia mempengaruhi rasa kenyamanan diruang luar iklim tropis lembab secara signifikan (Sangkertadi, 2013). Menurut hasil penelitian tentang pengaruh kecepatan angin terhadap tingkat kenyamanan termal di luar ruang beriklim tropis lembab didapati bahwa pada saat tengah hari panas, dimana suhu udara dan suhu radiatif mencapai sekitar $32^{\circ} \mathrm{C}$, pejalan kaki di ruang luar memerlukan kecepatan angin lebih dari $2.5 \mathrm{~m} / \mathrm{s}$ untuk mendapatkan rasa nyaman. Sedangkan yang beraktifitas duduk, dengan angin $1 \mathrm{~m} / \mathrm{s}$ sudah memberi rasa nyaman. Selanjutnya pada suhu $32^{\circ} \mathrm{C}$ rasa nyaman bagi pejalan kaki setelah mendapat angin lebih dari $3 \mathrm{~m} / \mathrm{s}$, Sedangkan bagi yang duduk-duduk, merasa nyaman pada kecepatan angin lebih dari $2 \mathrm{~m} / \mathrm{s}$. Berdasarkan hasil penelitian didapati bahwa RTH FMIPA, FAPERTA dan FH dapat dinyatakan nyaman dari segi kecepatan angin.

\section{Desain RTH dan Kenyamanan Termal}

Tingkat produktivitas dan kesehatan manusia sangat dipengaruhi oleh kondisi iklim setempat. Apabila kondisi iklim (berkaitan dengan 
suhu udara, kelembaban udara, dan kecepatan angin) sesuai dengan kebutuhan fisik manusia, maka tingkat produktivitas dapat mencapai titik maksimum. Suhu udara yang panas terutama pada siang hari menimbulkan rasa ketidaknyamanan (Irwan dan Kaharuddin, 2010). RTH di Kampus Unsrat yang memberikan kenyamanan dapat berkontribusi dalam menunjang aktivitas ruang luar, kesehatan fisik dan psikis bagi mahasiswa dan dosen. Sebaliknya, RTH yang tidak nyaman atau sangat tidak nyaman, membatasi aktivitas di ruang luar. Faktor-faktor iklim mikro tidak terlepas dari peran vegetasi yang menyusun $\mathrm{RTH}$. Vegetasi sebagai pengendali iklim (climate control) untuk kenyamanan manusia. Pada RTH, vegetasi berperan sebagai kontrol radiasi sinar matahari, suhu dan angin. Tanaman akan menyerap panas dari radiasi matahari dan memantulkannya sehingga dapat memantulkan suhu, mengurangi sinar matahari yang menembus ke bawah, dan memperbaiki iklim mikro (Iswanto, 2006). Selain vegetasi, struktur bangunan dan badan air juga mempengaruhi kenyamanan termal. Di daerah beriklim tropis, temperatur udara yang relatf tinggi merupakan penyebab utama situasi tidak nyaman secara termal. Bangunan dan area perkerasan Kampus Unsrat yang semakin besar sementara lahan untuk penghijauannya semakin sempit, hal ini akan berakibat pada temperatur ruang luar yang cenderung menjadi lebih panas sehingga mengganggu kenyamanan beraktifitas di luar ruangan.

Pada siang hari yang terik umumnya kita merasakan ketidaknyamanan terhadap udara panas perkotaan, sehingga eksistensi vegetasi sangat berarti (Tahuid, 2008). Vegetasi mampu menciptakan lingkungan yang nyaman melalui penurunan suhu udara. Perlu memanfaatkan pohon-pohon berkanopi melebar untuk mencegah paparan sinar matahari yang terlalu banyak ke area tempat berlangsungnya aktivitas (Gambar 13). Untuk mengurangi aliran udara panas dari jalan, bisa dikombinasikan dengan semak dan tanaman gantung atau merambat. Bila fokusnya untuk menghalangi sinar matahari dari arah tertentu misal sinar matahari dari arah barat di sore hari, maka dapat memanfaatkan tirai tanaman dengan tanaman rambat atau jejeran pohon. Tindakan pemeliharaan rutin yaitu pemangkasan pohon untuk mengontrol percabangan sebaiknya dilakukan di musim hujan. Dengan demikian bagian bawah kanopi menerima paparan matahari lebih banyak pada musim yang lebih sejuk dan yang terhindar dari kelembaban berlebihan, sebaliknya tetap akan lebih banyak terlindungi pada musim yang panas sehingga lebih sejuk.

Meskipun paparan sinar matahari menjadi variabel yang mengendalikan kenyamanan termal, tapi pada kondisi tertentu, kecepatan angin menjadi hal yang sangat penting (Walls, Parker, and Walliss, 2015). Sementara, pohon-pohon tertentu dapat berfungsi sebagai penahan angin yang menurunkan kecepatan angin di dalam tajuk. Dengan demikian, adalah hal yang kritis untuk mempertimbangkan aliran angin sejak tahap pembuatan master plan dan desain/redesain RTH. Tidak bijaksana bila pohon dengan tajuk masif dijejerkan rapat sehingga memblok aliran angin dari area terbuka misal lapangan rumput atau kolam, terutama bila RTH yang dimanfaatkan untuk aktivitas sudah terkungkung dengan bangunan-bangunan. Bila tetap menginginkan pohon dengan tajuk piramid untuk mendapatkan kesan formal dan atau mempertegas garis batas penggunaan, bisa ditanam dengan jarak lebar antar pohon agar angin mengalir bebas (Gambar 14). Pada kondisi dimana RTH yang akan dimanfaatkan untuk aktivitas outdoor sulit mendapatkan aliran angin karena berada pada cekungan atau karena dipengaruhi bangunanbangunan, meninggikan area untuk duduk dan bersantai dan mengurangi halangan masif dapat juga menjadi pilihan (Roy, Byrne, and Pickering, 2012; Walls, Parker, and Walliss, 2015), seperti terlihat pada Gambar 15. Secara bersamaan dengan pengaturan drainase, teknik ini akan sangat bermanfaat.

Selain vegetasi, keberadaan bangunan, tutupan lahan mempengaruhi suhu udara. Vertical garden atau vertical culture atau tanaman merambat sangat berguna dalam mengelola lansekap dengan keterbatasan lahan. Selain itu, dapat meningkatkan kenyamanan termal melalui pengurangan pantulan bangunan (Gambar 16). 

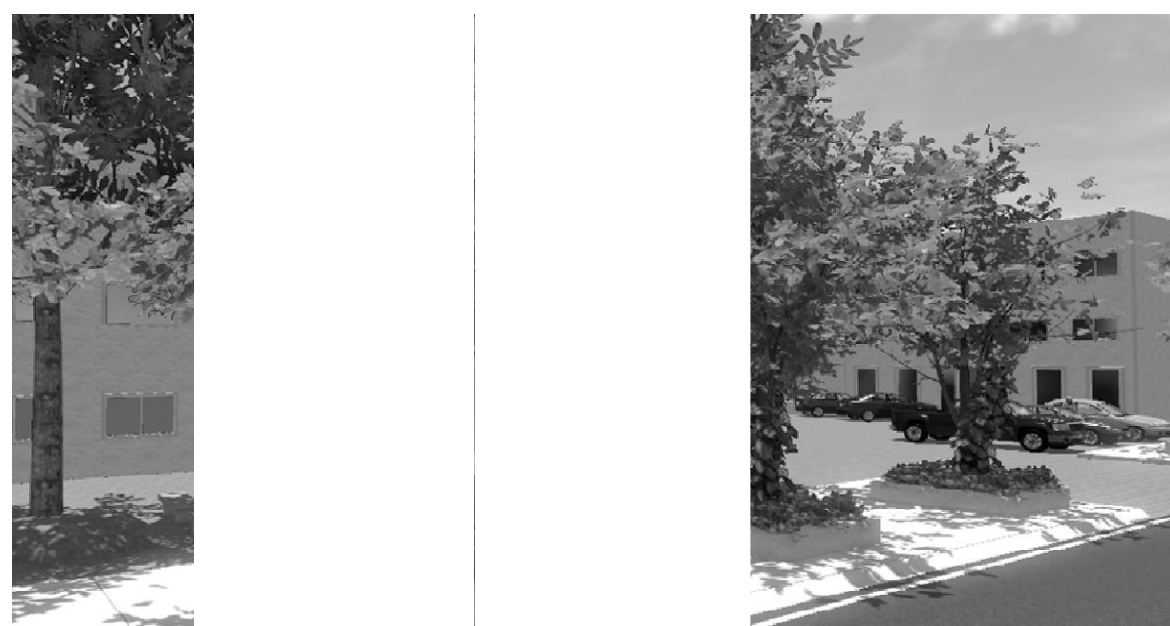

Gambar 13. Penggunaan Pohon-Pohon Berkanopi Lebar untuk Menciptakan Bayangan (Figure 13. Use of Trees to Create Shadows)

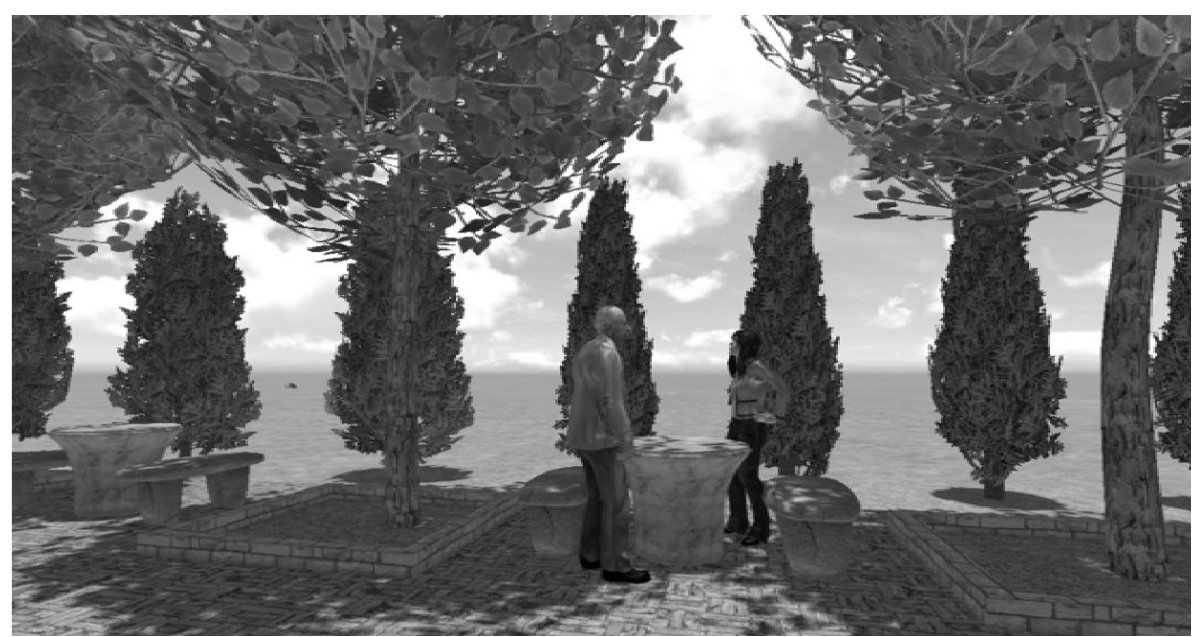

Gambar 14. Pengaturan Aliran Angin dan Paparan Sinar Matahari dengan Pohon (Figure 14. Controlling Wind Flow and Sun Radiant with Trees)

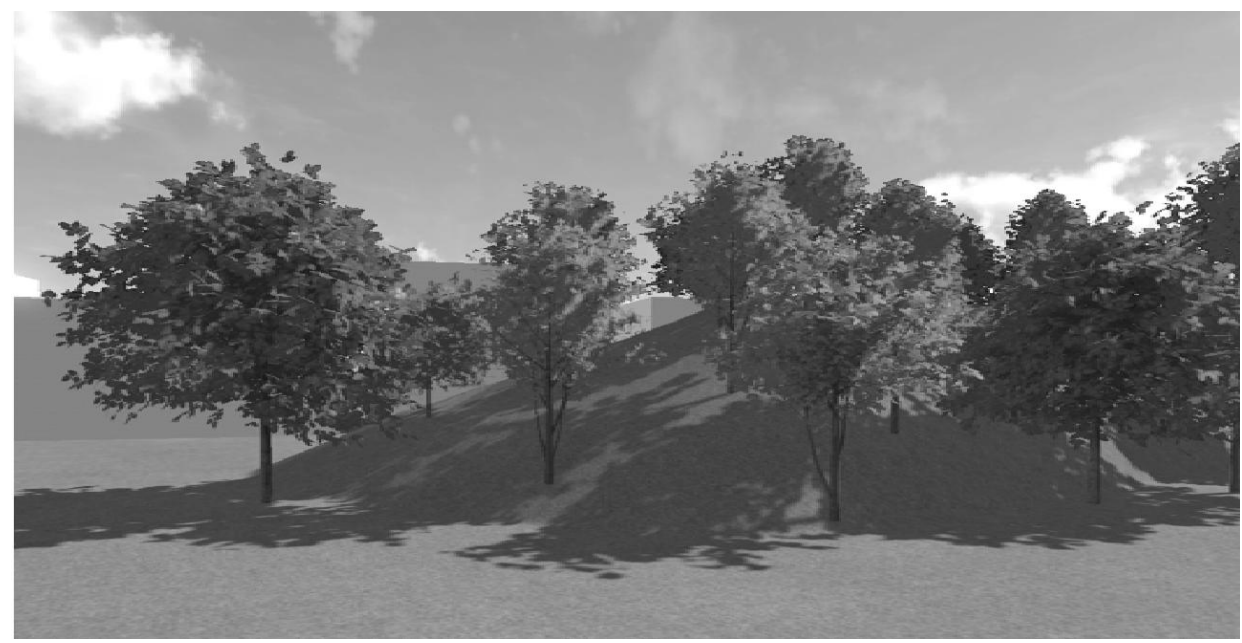

Gambar 15. Teknik Meninggikan Muka Lahan.

(Figure 15. Adding Height of Ground Level Technique) 


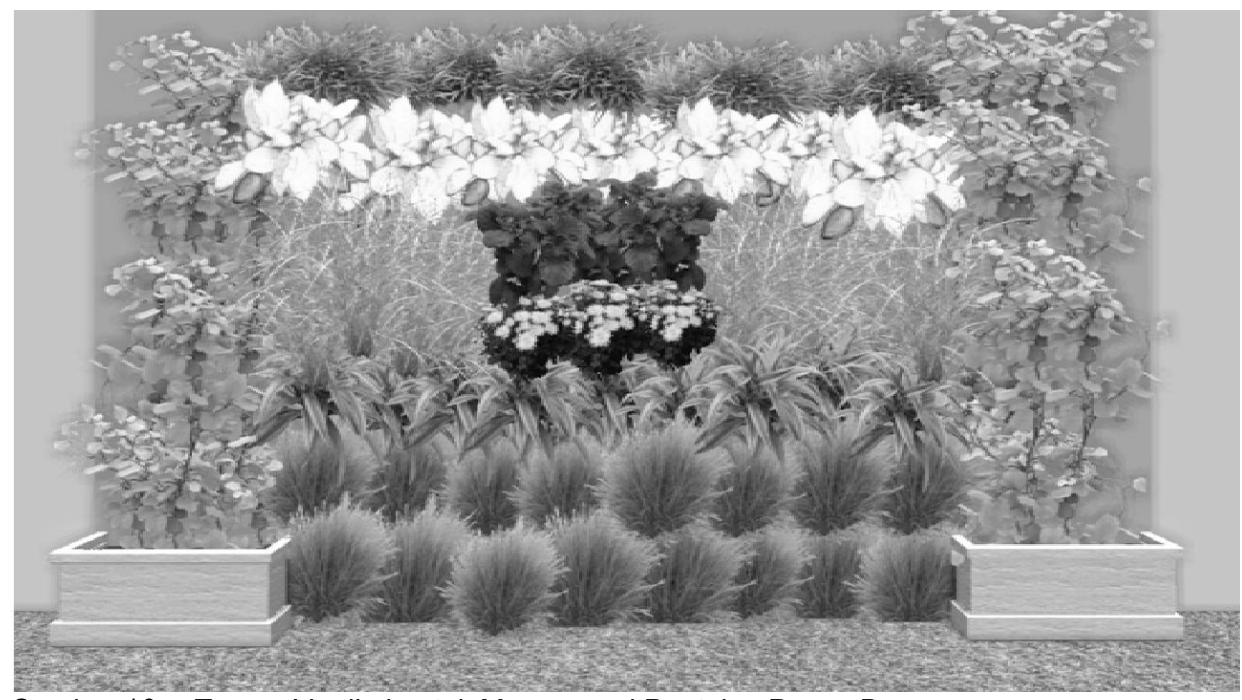

Gambar 16. Taman Vertikal untuk Mengurangi Pantulan Panas Bangunan

(Figure 16. Vertical Garden to Reduce Building Heat Reflection)

\section{KESIMPULAN DAN SARAN}

\section{Kesimpulan}

Hasil perhitungan kenyamanan termal di Kampus Unsrat menunjukan bahwa RTH yang masuk kategori nyaman yaitu FMIPA. RTH FAPET, FPIK, dan FEB tergolong kategori agak tidak nyaman. RTH yang tergolong kategori tidak nyaman yaitu yang terletak di Bank BNIdan FKM A. RTH FAPERTA, FATEK, FISIP, FH, FKM A, dan FKM B dikategorikan sangat tidak nyaman berdasarkan kenyamanan termal.

Dalam mendesain untuk mengameliorasi iklim mikro RTH kampus UNSRAT yang mendukung aktivitas ruang luar, beberapa hal yang dapat diterapkan adalah sebagai berikut. Shadowing lebih diperbanyak, apalagi di area dengan struktur buatan (gedung, jalan, paving) mendominasi tutupan lahan dengan menggunakan lebih banyak shadowing tree daripada tiang atau piramid. Bila fokusnya untuk menghalangi sinar matahari dari arah tertentu misal sinar matahari dari arah barat di sore hari, maka tirai tanaman atau jejeran pohon. Meninggikan muka tanah dapat menjadi pilihan untuk menambah peluang mendapatkan kecepatan angin yang lebih besar. Memanfaatkan aliran udara ruang terbuka yang relatif sejuk dan bersih misal lapangan rumput dan kolam dengan memberi bukaan ke arah RTH dapat me- nambah kenyamanan termal. Untuk mengurangi pantulan gedung-gedung, bisa dibuat vertical garden atau memanfaatkan tanaman merambat.

\section{Saran}

Untuk meningkatkan kenyamanan di kampus Universitas Sam Ratulangi sebaiknya dilakukan evaluasi pengelolaan RTH seperti pengaturan jadwal pemangkasan, perencanaan penanaman ulang, juga redesain.

\section{DAFTAR PUSTAKA}

Anggriani, N. 2010. Ruang Publik dalam Perancangan Kota. Yayasan Humaniora. Surabaya.

ASHRAE. 1989. Ashrae Standard Thermal Environmental Conditions For Human Occupancy. Dalam : Rilatupa, J (ed). Aspek Kenyamanan Termal Pada Pengkondisian Ruang Dalam. Jurnal Sains dan Teknologi EMAS. Jakarta.

Arn, G. 2015. Kelembaban dan Evaporasi. http://kuliahpertanian14.blogspot.co.id/201 5/ 12/resume-kelembaban-dan-evaporasi. html. 13 Desember 2016. 
Artiningrum, T. 2013. Tanaman Penyerap CO2. http://cifajota.blogspot.co.id/2013/01/tanam an-penyerap-co2.html. 20 Desember 2016.

Brown, R.D., Vanos, J., Kenny, N. and Lenzholzer. S. 2015. Designing Urban Parks that Ameliorate the Effects of Climate Change. Landscape and Urban Planning, 138, 118131.

Chen, L., Ng, E. 2012. Outdoor Thermal Comfort and Outdoor Activities: A Review of Research in Past Decade. Cities Vol. 29(2): 118-125.

Dahmann, N., J. Wolch, P. Joassart-Marcelli, K. Reynolds, and M. Jerrett. 2010. The Active city? Disparities in provision of urban public recreation resources. Healthand Place, 16(3), 431-445.

Escobedo, F. J., T. Kroeger, and J.E. Wagner, 2011. Urban Forests and Pollution Mitigation: Analyzing Ecosystem Services and Disservices. Environmental Pollution, 159 (8), 2078-2087.

Fadholi, A. 2013. Studi Pengaruh Suhu Dan Tekanan Udara Terhadap Operasi Penerbangan di Bandara H.A.S. Hananjoeddin Buluh Tumbang Belitung Periode 1980-2010. Jurnal Penelitian Fisika dan Aplikasinya (JPFA), 3(1): 1-10.

Fuller, R. A., K.N. Irvine, P. Devine-Wright, P.H. Warren and K.J. Gaston. 2007. Psychological Benefits of Green Space Increase with Biodiversity. Biology Letters 3, 390-394.

Honjo, T. 2009. Thermal Comfort and Outdoor Environment. Global Environmental Research 13: 43-47. lek, Y., I.L. Moniaga, dan Sangkertadi. 2014. Kepadatan Bangunan dan Karasteristik Iklim Mikro Kecamatan Wenang Kota Manado. Jurnal Sabua 6(3): 285-292.

Irwan, S. dan Kaharuddin. 2010. Studi Kenyamanan Untuk Aktivitas di Lanskap Hutan Kota UGM, Studi Kasus : Klaster Agro UGM. Jurnal IImu Kehutanan 4(2): 98-110.

Karyono, T. H. 2016. Kenyamanan Termal Dalam Arsitektur Tropis. PT Raja Grafindo. 2016.

Lee, A., and R. Maheswaran. 2011. The Health Benefits of Urban Green Spaces: A Reviewof the Evidence. Journal of Public Health 33 (2), 212-222.

Maidinita, D., G. Hardiman, dan E. Prianto. 2009. Pola Ruang Luar Kawasan Perumahan Dan Kenyamanan Termal di Semarang. Jurnal Riptek, 3(2): 21-26.

Mom, C. P. 1947. The Application of the Effective Temperature Scheme to the Confort Zona in the Nedherland. Dalam: T. H. Karyono (ed). Kenyamanan Termal dan Penghematan Energi: Teori dan Realisasi dalam Design Arsitektur. BBTE. Jakarta.

Olgay, V. 1962. Design With Climate Bioclimatic Approach to Arctitectural Regionalism. Princeton University Press. Princeton, New Jersey.

Rilatupa, J. 2008. Aspek Kenyamanan Termal Pada Pengkondisian Ruang Dalam. Jurnal Sains dan Teknologi EMAS 18 (3): 191-198.

Roy, S., J. Byrne and C. Pickering. 2012. A Systematic Quantitative Review of Urbantree Benefits, Costs, and Assessment Methods Across Cities in Different Climaticzones. Urban Forestry and Urban Greening 4 (11), 351-363. 
Sangaji, Y., Sangkertadi., A. Sembel. 2015. Kajian Kenyamanan Termal bagi Pejalan Kaki pada Jalur Pedestrian Universitas Sam Ratulangi. Perencanaan Wilayah Jurusan Arsitektur. Manado.

Sangkertadi. 2013. Kenyamanan Termis di Luar Ruang Beriklim Tropis Lembab. Alfabeta. Bandung.

Sari, A. N. 2013. Evaluasi Hutan Kota Berdasarkan Fungsi Ameliorasi Iklim Mikro di Kota Semarang. Institut Pertanian Bogor. Bogor.

Syafriny, R. dan Sangkertadi. 2012. Perbandingan Pengaruh Suhu Lingkungan Pada Kenyamanan Termis di Luar Ruang dan Ruang Dalam di Iklim Tropis Lembab Bagi Manusia Beraktivitas Moderat. Jurnal Media Matrasain 9 (1): 26-35.

Uhangkayo. 2012. Manfaat Ruang Terbuka Hijau (Ameliorasi Iklim dan Penghematan Listrik). http://lembah-kerinci.blogspot.co. id/2012/03/manfaat-ruang-terbukahijauameliorasi.html. 13 Desember 2016.
Villeneuve, P. J., M. Jerrett, J.G. Su, R.T. Burnett, H. Chen, and A.J. Wheeler. 2012. A Cohort Study Relating Urban Green Space with Mortality in Ontario, Canada. Environmental Research 115, 51-58.

Walls W., N. Parker, and J. Walliss. 2015. Designing with Thermal Comfort Indices in Outdoor Sites. In R.H. Crawford and A. Stephan (eds.), Living and Learning: Research for a Better Built Environment: 49 th International Conference of the Architectural Science Association 2015, pp.1117-1128. The University of Melbourne.

Wang, Y., R. de Groot, F. Baker, R. Worcje, and R. Leemans. 2016. Thermal Comfort in Urban Green Spaces: A Survey on a Dutch University Campus. International Journal of Biometeorology

Wolch, J. R., J. Byrne, and J.P. Newell. 2014. Urban Green Space, Public Health and Environmental Juctice: The Challenge Making Cities Just Green Enough. Landscape and Urban Planning 125: 234244. 
